\title{
It takes two to tango: phenomenology relational roles of academic deans and program chairs in the Philippines
}

\author{
Roselle M. Soriano \\ Assistant Professor IV, College of Arts \& Sciences. \\ Annalene Grace Co; \\ Assistant Professor III, College of Teacher Education \\ *Corresponding author Email: *sorianoroselle1@gmail.com
}

\begin{abstract}
Managing academic affairs encompasses overwhelming array of tasks. Cognizant of the interesting and challenging position occupied by the deans and program chairs; this paper shed some light to help illuminate the way our academic leaders manage relationship in the university. The purpose of this phenomenological study was to explore the lived experiences of academic deans and program chairs of Quirino State University, Cabarroguis, Campus as they manage relationships in their institution. Further, it described the typical roles they portray as leaders and managers in their organization. Driven by the questions, "How is your relationship with the administrators, subordinates and students? How do you encourage collaboration with and among your subordinates? In what ways do you manage relationship with yourself, with your subordinates, and with your superiors? a series of in-depth, semi-structured interviews were conducted. Further, four interesting themes emerged on the roles portrayed by academic leaders namely: a) people-centered leader, b) value-driven leader, c) goal-driven leader, and d) power-centered leader. However, the emerged roles revealed by the deans and program chairs invite for a more empirical study to measure its universality across a more collective participant.
\end{abstract}

Keywords: challenges, module writing, instructional materials, faculty members

\section{Introduction}

Higher education institutions have central importance in social, cultural, and economic development for nations everywhere. Throughout time, educational institutions respond to the demands of evolving and changing the environmental conditions of society. (Arntzen, 2016).

Moreover, the leadership linchpin that holds an organization together lies central between those perceived as leaders and those upon whose work the reputation of the organization rests. In universities today, academic deans fill this role (Wolverton, 2001).

Furthermore, the academic dean is regarded as a unique position at the forefront of institutional transformation due to the emerging administrative culture in higher academic institutions (Guzman \& Hapan, 2013). The transformation from plain faculty to academic program chairs and deans require time and dedication; hence, not all academic leaders successfully make the complete transition to leadership. Deans and program chairs typically come to the position without management training, without prior managerial experience, without recognition of the metamorphic changes that occur as they transform from an academic to a leader, without a clear understanding of the ambiguity and complexity of their roles, and without an awareness of the cost to their academic and personal lives (Gmelch, 2013).

Remarkably, today, the academic dean is involved with the college, its external constituents, the president, the faculty and curriculum in many ways different from other institutional member (Montez, 2003).

While there have been numerous studies conducted in the academic leader's roles in recent years, little has been conducted in the local setting specifically on how academic leaders manage their relationships in the organization. Hence, this study answers the central question: What typifies academic deans and program chairs portrayal of their roles as relationship managers in their organization? The overall objective of this study is to explore the lived experiences of academic deans and program chairs of Quirino State University, Cabarroguis Campus as they 
manage relationships in their institution. Further, it describes the typical roles they portray as leaders and managers in their organization.

Moreover, results of this qualitative study provide valuable understanding and insights that probe on the relational interactions and dynamic social experiences of academic deans and program chairs. Specifically, the emerged essence of deanship roles will help academic leaders to build stronger leader-subordinate relationships and to improve their human relation skills within the organization.

\section{Literature review}

\subsection{Academic leadership}

Leadership is defined as a process whereby certain individual influences a group of subordinates to attain a common goal. Hence, leadership is not considered a trait internalized by leaders but rather includes an interaction between the follower and a leader. Furthermore, the leader is influenced by his subordinates whom he or she leads which indicate that leaders are not born, but made. Further, leaders should develop character and vision as a result of growth and experiences and through following and learning from subordinates who have influenced them (Kleihauer, 2013).

On the other hand, Seale \& Cross (2016) defined academic leadership as "the act of building a community of scholars to set direction and achieve common purposes through the empowerment of faculty and staff."

Moreover, Desai et. al (2016) emphasized that program chairs and deans are faculty supervisors involved in supervising the operation of their respective units of education. Further, they can influence the way in which subordinates are expected to interact. Finally, program chairs, in particular, are well-positioned to provide leadership in creating an inclusive and supportive culture for faculty, staff, and students.

\section{Methodology/materials}

This study used qualitative design employing phenomenological approach to describe and interpret the roles of academic deans and program chairs in managing relationships in their organization. The study was conducted among two academic deans and five program chairpersons in all colleges in Quirino State University, Cabarroguis Campus.

In order to acquire the essence of the phenomenon under investigation, a letter of request was sent to the Campus Administrator and purposely to the selected participants informing them of the nature of the research, the topic to be discussed and the extent of their involvement. Once their consent was obtained, an appointment was scheduled for a one-on-one interview based on their convenience and availability. The interview meetings were conducted in the respective offices of deans and program chairs and lasted for one to two hours. The in-depth and semistructured interview was conducted in English but they were allowed to answer in Iloko as their native language/mother tongue to ensure the fullness of data. The said interview primarily focused on their roles and experiences as academic deans and program chairs in managing relationships in their organization. Their sharing revolved around the following key questions in the interview guide: (a) How is your relationship with the administrators? (b) How is your relationship with your subordinates? (c) How do you encouraged collaboration with and among your subordinates (d) In what ways do you manage relationship with yourself, with your subordinates and with your superiors? The flow of conversation was determined by the participant, although in some occasions, the researcher needed to ask questions for the purposes of clarification and to probe deeper on certain responses.

Moreover, field texts were transcribed and analyzed using a repertory grid and through constant comparative analyses, a set of conceptual themes about faculty member' challenges and coping mechanisms were emerged.

\section{Results and findings}

Results in this study explored the essence of the lived experiences of a group of academic deans and program chairs as they manage relationships in their organization. Based on the responses given by the participants, the four interesting themes appeared on the typical roles portrayed by deans and program chairs. The themes include a.) people-centered leader, b.) value-driven leader, c.) goal-driven leader, and d.) power-centered leader. 


\subsection{Roles portrayed by deans and program chairs}

Analysis was done for the specific themes generated from responses to obtain a more encompassing theme. They are as follows:

\section{Theme \# 1. The person-centered leader: an opportunity provider}

According to Fazio et al. (2018), person-centered leadership involves assurance and commitment from all the members of the organization. Motivated by the desire to nurture a climate of empowerment, the participants in this study are in one in creating a meaningful space where both opportunities and challenges happen. The interaction is facilitated by consultation, collaboration, teamwork, cooperation and participation.

The person-centered leadership is manifested among the participants by their genuine practice of consultation from their superiors and subordinates in matters which relate to the concerns of their organization. This is expressed by the following verbalizations:

"If there are issues/concerns about the department, I ask suggestions from them. I always consult authorities regarding serious issues in the department." (P5, P7) "I ask the suggestions of my subordinates whenever there are problems in the department that need to be solved. Yes, they are free to give their ideas and opinions." (P4, P7) "I consolidate all their suggestions before coming up with the final decision."(P1, P2, P3, P76) "We discuss the pros and cons of such decision as well."(P3) "Though for emergency cases that needs to be addressed, I have to ask the higher ups for their final say." (P7)

The immense role of collaboration in an organization is best visualized by the participants' selfless act to support both students and faculty in their professional and personal activities. In doing so, the academic leaders are able to establish cooperation and participation in the organization. This is congruent to the enunciations of Hurley (2011) that to lead collaboratively is to lead with an unshakeable commitment to shared purpose and collective goals, for its purpose that inspires and sustains high-quality participation. Further, Ribeiro (2018) revealed that cooperation is important among teachers because it creates equally meaningful relationships among teaching professionals.

Other participants mentioned:

"I am not selfish. (P1, P6, P7) "I used to tell them that they should finish their doctorate degree because I will not be forever in my position as a program chair, they have to take over too because I believe in their potentials for they also work hard for this department." (P2, P3, P6) "Further, I see to it to recommend my subordinates to all seminars and trainings for them to be updated on the latest trends. I also encourage my subordinates to equip themselves in all possible chances. It pays to be updated at a young age... for the sake of NBC or for selffulfillment." (P7)

Another program chair expressed:

"I also do mentoring in the department. They are free to approach me and I am very much willing to assist them in terms of instruction. In fact, for the newly hired instructors of the department, I mentor and guide them in their lessons." (P5)

Other participants also shared:

"Yes, I am very supportive to all student activities. (P5, P7) "In fact, during intramural meet, I include all our students in the planning and decision making."(P3)“We are united in all activities of the department."(P2) "Moreover, the result of the board exam is a concerted effort of all my colleagues in the department. From the review alone, we dedicate our time, money and effort just to give them what they really needed before they will take the board. All of us have our own schedule to conduct the review regardless of our teaching loads. Actually, the review sessions that we are conducting are not included in our regular teaching loads."(P3)

In this study, the influence of consultation, collaboration, and teamwork develop an effective means in empowering deans and program chairs to hone and develop their faculty and students. Anfara in 2008, emphasized that teachers in schools with a culture that encourages collaboration are more positive about their profession, enjoy their jobs more, have higher expectations for their students, and have greater confidence and commitment to improvement. Further, Assbeihat (2016) stressed that teamwork is essential in an organizations as compared to the task done individually, to achieve the outcomes efficiently and effectively. Similarly, Neto et al. (2018) mentioned that collaboration among educators is constantly regarded as an powerful component of 
education that bring a positive impact on some variables such as students' academic performance and job satisfaction.

\section{Theme \# 2. The values-driven leader: a truth seeker}

Values-driven leadership happens when academic leaders are driven by values that shape their mindset and inform their decisions and actions (Akpeki , 2017). Further, Gehrke (2014) revealed that values of deans play a significant role in organizational decisions. In this paper, the character of a dean and a program chair is best observed in the application of and adherence to truth seeking practices which are governed by values of openness, honesty, transparency, humility, and commitment. This supports the idea of Ribeiro (2018) that affective commitment facilitates the relationship between employees' performance and authentic leader. This means that leaders' authenticity supports subordinates' affective commitment, as a result, intensifies their individual performance.

It is remarkable to note that their lives as academic leaders in an institution is not only focused toward accomplishing tasks but also engrossed on managing relationships. Their ability to build a climate of understanding depends on their skills on how they portray their roles whose vital goal is to seek the truth as the essential block of their value-driven character. As articulated by the participants:

"I admit I am young in my position, so I solicit ideas from them. I encourage brainstorming." (P3) "If they commit mistakes, I inform them but I also I investigate and look for evidences." (P1, P6,) "I balance everything. (P2) "I see to it that everybody deserves a second chance." (P3)

Notably, the participants recognize the important role of honesty in the organization. It is used to win the trust of the subordinates. Trust is a person's willingness to be vulnerable to another based on the confidence that is benevolent, reliable, and competent, honest, and open (Yin et al. 2011). As expressed:

"I am honest to them." (P3) “I don't pretend so they would trust me." (P7) "I should be of course a good model to them in all aspects. For instance, attending to my classes regularly and submitting reports on time."(P2

The participants' skill of managing relationship is observed by their trust and high degree of openness which is attained through creation of space so that both faculty and students are able to express their concerns and needs in the organization. This is consistent with Ghazinejad (2017) who found out that trust is a complex phenomenon that enables cooperative behavior, decreases transaction costs, reduces harmful conflict, and upholds effective responses to crisis. As shared by the participants:

"I am so grateful I have a very strong faculty line up. They are workaholic. We have open communications to address different needs in the department." (P7) "My relationship to them is "family-like" so that they will feel comfortable and most probably we could work harmoniously." (P1, P4, P6) "The students are open to me. They can talk to me in the office." (P3) "In terms of grades, I am fair to them." (P1, P5, P4) "I am that kind of person that is easy to adjust. Sometimes, I need to go down to the level of my subordinates for us to understand each other."(P2) Notably, the respondent deans and program chairs remind their subordinates of the good values one must possess in order to accomplish their goals meaningfully and effectively. This is in consistent with Engelbrecht (2017) who affirms that a moral manager manages morality, and it is his efforts to influence his subordinates and guide them in terms of their ethical behavior, such as communicating moral standards and disciplining subordinates who exhibit unethical behaviors. Thus, caring attitude and moral role of leaders towards the professional requirements of the subordinates help increase the citizenship behavior on individual level to a great deal (Afsar, 2014).

As the participants articulated:

"I always remind them of their "loyalty to the profession" that they should always take care of their profession/reputation as instructors. They should act as professionals. They should be models in all aspects."(P4) "What matters most to me is "attitude". (P5)

Two program chairs also verbalized:

“To manage people is a great task and become a model at the same time. I mean you can't teach what you do not know. But to be able to motivate people to accomplish big task every day is very fulfilling."(P7)“Being a program chair is a great opportunity and challenge at the same time. It takes a lot of pressure and determination to be able to do the task of being a mother and a dean."(P7) Further, you must also be a good example to them." (P4) 
Further, the above verbalizations of the participants run parallel to the idea of Copeland (2014) that leaders are needed to "lead values and integrity". Additionally, Kaiser \& Overfield (2010) posited that the leadership value chain begins by considering the things that make individual leaders unique-their personalities, abilities, knowledge, skills, and relationships. These individual differences represent who leaders are, and have implications for how they lead. Finally, Mussig (2003) affirmed that leadership is both a relationship and a behavior that has values as a core dimension.

\section{Theme \# 3. The goal-driven leader: a reflective practitioner}

To build vision, leaders listen, taking in the knowledge and experience of those around them. Then they process this knowledge, using their imagination and judgment to create a realistic plan (Clark, 2008).

Inspired by the goal to build a climate of directions, the program chairs and deans adopt the character of a goaldriven leader. Interestingly, the participants carry out visions through optimism and careful planning. As emphasized by some of the participants:

"I did not expect for this position." (P3) My experience as a head of this college is not enough... my knowledge, skill, and experience in managing the department is not sufficient." (P4) "I don't have any training on management, yet my boss, subordinates and students are expecting too much from me...In terms of decision making, careful planning is necessary...I must be firm... and I should be a risk taker. For this, I believe I could be able to achieve my plans for the department."(P5)

The above verbalizations from the participants that successful dean is a skilled manager. Furthermore, the participants reflect on their past experiences for them to draw strength and wisdom to accomplish their visions. This is in congruent to the idea of Gmelch (2013) that the ability to reflect upon and grow from past experience is imperative to improve academic leadership. As the participants conveyed:

"Most of the time, I do reflection, I plan for new management style in order for us to be united in the department." (P3) For me, yes... it's really hard to say "sorry", but I say it whenever I realized the result of my decision is not good. It's a matter of acceptance on my part if I committed wrong decision...but of course, I see to it that I have learned from my mistakes." (P5)

Moreover, in managing the organization, the respondent deans and program chairs are guided with the rules, goals and objectives of the organization. As articulated by some of them:

"Talking about management, first, I check the goals of the department and I always depend my decision on these goals." (P1, P6) "I always based or depend our decision from rules and I am being guided by the rules. (P3)

Endowed with the gift of vision, the participants are able to accomplish thoughtful plans and carry out into significant and purposeful actions in which they, together with the subordinates, embark on a mission toward a definite direction resulting to meaningful and active relationships in the organization. As indicated by two of the participants:

"The result of the board exam is really challenging on my part, so I have to do my best to maintain our status. It's really a great challenge as a program chair. (P3, P7) "But through the help of my subordinates we can achieve our goal that is to maintain if not increase the result of our board exam." In fact, we adopted a new style in the conduct of the review. We work collaboratively. Each of us here has our own expertise in all our major subjects, so what I did is encourage my entire faculty to conduct the review. With this, we are one in achieving our goals. " (P3) Remarkably, the academic leaders are able to motivate their subordinates to accomplish their vision in the organization. Moreover, within the power of relationship management, the deans and program chairs engage in a mission with subordinates to carry plans into realization. This asserts the study of Fayazz (2014) that leadership is an important management function to maximize efficiency and achieve organizational goals. It is a process where in the leader influences followers in achieving the shared task and objective (Yukl , 2010).

\section{Theme \# 4. A power-oriented leader: a model of authoritative leadership}

Leadership is authoritative when subordinates willingly obey because they believe leader's orders or directions represent followers' self-interest and also the larger mission of the organization or institution (Milofsky, 2018). Authoritative leaders mobilize people toward a vision (Goleman, 2000).

Confronted with enormous duties and responsibilities, the respondent deans and program chairs are also expected to cultivate a climate of followership where careful use of power delineates their authority as leaders. Being 
authoritative leaders in their respective organizations, they were able to manage their tasks successfully and assure that they treated their subordinates with respect. This is in agreement with Engelbrecht (2017) who found out that when subordinates are treated in a respectful and fair way by their leaders, they most likely think about their relationship with their supervisor in terms of social exchange rather than economic exchange. Furthermore, they reciprocate by putting extra effort into their job, through dedication and commitment in their work.

As respondents articulated:

"I am a "principled" leader, if I have decisions made, I stick to it...I stand firm with it."(P3) "They obey my rules; in that sense I know they respect me." (P3) "I have my own way of disciplining my subordinates and it's clear to them." (P2) "If they violated the rules, I let them know about it." P6

Notably, the statements above indicate that the respondent deans and program chairs established their authority in the organization. As authoritative leaders, they are able to set their rules and their subordinates recognize and accept these rules. These findings are in agreement with Huberts (2007) who emphasized that "discipline given to rule violators serve a significant symbolic role in organizations. Further, it strengthens standards, advocates the value of conformity to shared norms and upholds the perception that the organization is a fair place where offenders are held responsible for their actions."

Other participants also shared:

If there are serious issues and problems that need immediate action in the department, I am responsible and I have to decide alone." (P4) Yes, I always take the responsibility to decide for problems that need immediate action. In fact, during the On-the-Job Training of my fourth year students, I have to be firm with my decision not to include those students who were pregnant because it is really very risky on their part. (P2) in the department, I see to it that my co-workers respect whatever decision I'll make especially for serious matters and it's very clear to them The verbalizations emphasize that the academic leaders make decisions on serious issues and emergency matters that need immediate response. Hence, they gained respect and acceptance from their subordinates whenever they make crucial decisions in the organization. This supports the idea of Iqbal et al. (2015) that an autocratic style of leadership is suitable in some situations. Further, it is valuable when the organization is confronted with a crisis or when a serious problem rises which requires an immediate action.

In this study, the academic leaders do not purely assert their power over their subordinates but they are also open to share this power. This practice of the participants supports the claim of Marsh (2014) that authoritative leaders have a positive influence upon the school's climate and culture and develop supportive relationships. Such practice is emphasized by the following statements from the participants:

"I am a competitive leader. I wanted that my department should be performing to the best that I can." P7) I encourage my subordinates to work hard... and I think its effective...we're able to accomplish our goals."(P4) I delegate the tasks to all my faculty members and they really work hard for it. They accomplish their tasks with perseverance.

Other participants enthused:

"Yes, authoritative in the sense that I have to act according to my position, but still I am open for suggestions."(P5) "I am a strict leader in the sense that I follow proper rules and regulations of the school." If there are reports that are needed to be submitted, I used to call up the attention of that faculty concern. I also give them chance to explain."(P3)"Yes, I reprimand them through memos..." (P1

Admirably, the respondent deans and program chairs are able to balance their power in order to make their subordinates work and accomplish a task. Such practice affirms the concept of Dinham (2007) that "authoritative leaders exercise their authority appropriately and in a timely fashion. They know when to consult and when to be decisive. They have the skills to work with others and the courage to act alone."

\section{Conclusion}

Findings in this qualitative research affirm the major roles of academic deans and program chairs in managing relationships within the organization. Further, the study revealed that academic leaders portray their roles as a.) people-centered leader, b.) value-driven leader, c.) goal-driven leader, and d.) power-centered leader in managing relationships in their organization. Moreover, this inquiry has implications to academic leadership practice as it allows other academic leaders to analyze and relate their own management roles, attitudes, behaviors, beliefs 
values, and to dynamically maximize the success of their organization and to guarantee its existence through harmonious and sound relationships with superiors and subordinates. However, the emerged roles revealed by the deans and program chairs invite for a more empirical study to measure its universality across a more collective participant.

\section{References}

Afsar, B. ( 2014). Moral or Authoritative Leadership: Which One is Better for Faculty Members. American Journal of Educational Research, Vol. 2, No. 9, 793-800.http://pubs.sciepub.com/education/2/9/14 .๑ Science and Education Publishing .DOI:10.12691/edu.

Akpeki, T. (2017). Values-driven Leadership. Charity and Social enterprise Update.

Anfara, V. e. (2008). Research Summary: Courageous, Collaborative Leadership. . Faculty Publications and Presentations Curriculum and Instruction.

Arntzen., E. (2016). The Changing Role of Deans in Higher Education - From Leader to Manager. Universal Journal of Educational Research, 4(9): 2068-2075, 2016 http://www.hrpub.org DOI: 10.13189/ujer.2016.040918.

Assbeihat, J. (2016). The Impact of Collaboration among Members on Team's Performance. Management and Administrative Sciences Review. Vol.5, Issue 5.Pages 248-259. https://www.researchgate.net/publication/311811209.

Daniel, R. R. ( (2018).). Authentic leadership and performance: the mediating role of employees' affective commitment. . Social Responsibility Journal, Vol. 14 Issue: 1, pp.213-225. https://iconline.ipleiria.pt/bitstream.

Desaib, A. B. ( 2016). he leadership role of college deans and department chairs in academic culture change . Studies in Higher Education, http://dx.doi.org/10.1080/03075079.2016.1152464.

Dinham, S. (2007). Authoritative Leadership, Action Learning and Student Accomplishment. Australian Council for Educational Research.

Fayyaz, H. ( 2014). Effect of Task Oriented and Relational Leadership Style on Employee Performance:Moderating Impact of Communicator Competence. Journal of Marketing and Consumer Research.

Fazio, e. a. (2018). The fundamentals of person-centered care for individuals with dementia. Volume 58, Issue 1, February 2018, Pages S10-S19.

Gehrke, S. (2014). Supporting Non-Tenure-Track Faculty at 4-Year Colleges and Universities: A National Study of Deans' Values and Decisions . DOI: $10.1177 / 0895904814531651$. https://journals.sagepub.com/doi/abs/10.1177/0895904814531651.

Gmelch, W. ((2013)). The Development of Campus Academic Leaders. International Journal of Leadership and Change, Vol. 1: Iss. 1, Article 7.

Goleman, D. (2000). Leadership That Gets Results. Harvard Business Review.

Gosling, J. \&. ( 2003). The Five Minds of a Manager. Harvard Business School Publishing Corporation. Guzman, A. \&. (2013). It Takes Two to Tango: Phenomenologizing Collaborative Mindset of Filipino Academic Deans. Asia Pacific Educational Research, DOI 10. 10007/s40299-012-0056.

Hargreaves, A. (2002). Teaching And Betrayal. Teachers And Teaching: Theory And Practice. Vol. 8, No. 3/4, 2002 ISSN 13540602 (print)/ISSN 1470-1278 DOI: 10.1080/13540600210000052.

Helen, S. W. ( (2012)). Preschool Children's Transition to Formal Schooling: The Importance of Collaboration between Teachers, Parents and Children. . Australian Journal of Early Childhood., https://journals.sagepub.com/doi/abs/10.1177/183693911203.

Huberts L. (2007.). (A study of the impact of three leadership styles on integrity violations committed by police officers. International Journal of Police Strategies \& Management. , Vol. 30 No. 4, 2007 pp. 587-607 Emerald Group Publishing Limited 136.

Hurley, T. C. (2011). Collaborative Leadership-Engaging Collective Intelligence To Achieve Results Across Organizational Boundaries.

Iqbal N, A. S. ((2015).). Effect of Leadership Style on Employee Performance. . Arabian Journal of Business and Management Review., http://dx.doi.org/10.4172/2223-5833.1000146.

Kaiser, R. \&. ( 2010). The Psychologist-Manager Journal. The Leadership Value Chain, 13: 164-183.

Kleihauer, S. C. (2013). How Six Women Deans of Agriculture Have Attained Their Leadership Role: A Qualitative Study. Journal of Agricultural Education, Volume 54, Number 3, pp. 15 - 27 DOI: 10.5032/jae.2013.03015.

Milofsky, C. ( 2018). The Role of Authoritative Leadership in Voluntary Organizations.

Montez, J., Wolverton, M., \& and Gmelch, W. ( 2002). The Roles and Challenges of Deans: The Review of Higher Education. Vol. 26, Number 2,pp. 241-266.

Mussig, D. I.-0. ( 2003). A Research and Skills Training Framework for Values-driven Leadership. Journal of European Industrial Training. 
Neto, L. F. (2018). Teacher Collaboration in German Schools: Do Gender and School Type Influence the Frequency of Collaboration Among Teachers? Frontiers in Education. https://www.frontiersin.org/articles/10.3389.

Seale O. \& Cross, M. (2016). .Leading and managing in complexity: the case of South African deans. 41:8, 1514-1532, DOI: 10.1080/03075079.2014.988705 ISSN: 0307-5079: http://www.tandfonline.com/loi/cshe20.

Tabak, F. \&. ( (2017).). Learning by Doing in Leadership Education: Experiencing Followership and Effective Leadership Communication Through Role-Play. . Journal of Leadership Education, DOI: 10.12806/V16/I2/A1 https://journalofleadershiped.org/wp-cont.

Wolverton, M., Gmelch, W., Montez, J., \& Nies, C. (2001). The Changing Nature of Academic Deanship. SHE-ERIC Higher Education Report, Vol. 28, Number 1. Jossey-Bass Higher and Adult EducationSeries. !SBN-0-7879-5835-2.

Yin, H., Lee, J., \& \& Jin, Y. (2011). Teacher Receptivity to Curriculum Reform and the Need for Trust: An Exploratory Study from Southwest China. . The Asia-Pacific Education Journal, 20:1(2011), pp. 35-47.

Yukl, G. (2002). A Hierarchical Taxonomy of Leadership Behavior: Integrating a Half Century of Behavior Research. Journal of Leadership \& Organizational Studies, DOI: 10.1177/107179190200900102. 